\title{
Simplification Strategies in the Production of English Word-final Obstruent Clusters by Iraqi EFL College Students from A Markedness Theory Perspective
}

\author{
Zainab S. Ahmed al-Charrakh ${ }^{1 *}$, Mahdi I. Kareem al-Utbi ${ }^{2}$ \\ ${ }^{1}$ Department of English, College of Arts, University of Baghdad, Iraq \\ ${ }^{2}$ Department of English, College of Languages, University of Baghdad, Iraq \\ Corresponding Author: Zainab S. Ahmed al-Charrakh, E-mail: azynbsam@gmail.com
}

\section{ARTICLE INFO \\ Article history \\ Received: August 19, 2018 \\ Accepted: October 29, 2018 \\ Published: December 28, 2018 \\ Volume: 9 Issue: 6 \\ Advance access: November 2018}

Conflicts of interest: None

Funding: None

\section{Key words:}

English,

Arabic,

EFL,

Markedness,

Obstruents,

Phonotactics

\begin{abstract}
This study investigates the phonotactics of English obstruent clusters in the word-final position from a markedness theory perspective among Iraqi EFL College Students whose native language, Arabic, prefers only two-member word-final obstruent cluster as a maximum. The markedness of clusters is measured depending on Iraqi EFL College Students' utilization of the simplification strategies. This study tries to answer whether or not word-final obstruent clusters are marked or unmarked for Iraqi EFL College Students, and whether or not the markedness of the obstruent cluster increases as to its length. In order to answer these questions, a test has been distributed among 60 Iraqi EFL Fourth-Year College students, Department of English, College of ArtsUniversity of Baghdad for the academic year 2017-2018 involving a list of words and sentences containing word-final obstruent clusters. The study concludes that word-final obstruent clusters are marked due to the fact that the obstruents are universally marked in the coda. The fourmember obstruent clusters are more marked than the three-member obstruent clusters which are in turn more marked than the two-member obstruent clusters.
\end{abstract}

\section{INTRODUCTION}

English and Arabic are two languages of different phonological systems; they differ specifically in their sound systems and syllable structures which provide the phonotactic rules for obstruent clusters. That is, when English Foreign Language Learners (EFLLs, henceforth) do not know the phonotactics of English obstruents or when they assume that their own phonotactics apply in the target language, they may consciously or unconsciously depend on those of L1. Many EFLLs' deviations while pronouncing obstruent clusters are attributed to the mother tongue and to the markedness of the obstruent cluster itself. That is, the two-member obstruent clusters are available in the final position of English and Arabic words, but EFLLs may resort to the universal simpler structure of the cluster. Markedness is invoked as a predicator of the direction of the learners' order of difficulty in foreign language learning. If the target language involves marked obstruent clusters, it will be difficult to learn. If obstruent clusters are unmarked in the target language, they will exhibit little or no difficulty, even if they have no existence in the native language (Richard and Schmidt, 2010: s. v. markedness). A number of cri- teria that identify the marked and unmarked phonological elements have been given by linguists. The major frequent ones are: frequency, distribution, neutralization, simplicity, and the order of learning and cognitive complexity.

1) Frequency: The more frequent an element is, the more unmarked it will be, and the less frequent an element is, the more marked one it will be (Greenberg, 1966:13).

2) Distribution: this criterion shows that the distribution of an unmarked category occurs in a wider range both within a given language and across languages in comparison with a marked category (Lyons, 1977:306).

3) Neutralization: Neutralizations represent the environments in which the opposition between two or more categories is suspended, suppressed, or neutralized and consequently the unmarked member will appear (Greenberg, 1966: 58) and (Ferguson, 1984:248).

4) Simplicity presumes that the physically simpler clusters are unmarked and those which are interpreted as physically complex are marked (Battistella, 1990:27).

5) The order of learning and cognitive complexity: The order of learning mirrors cognitive complexity which shows that the structures which are learned earlier are 
unmarked, whereas those which are learned in later stages are marked (Callies and Gutenberg, 2013: 406) and (De lacy, 2006: 17).

In this paper, an investigation is made of the level of markedness in the production of word-final obstruent clusters by Fourth Year Iraqi EFL College Students in the Department of English, College of Arts-University of Baghdad for the academic year 2017-2018. The attempt is made so as to answer the following questions:

1. Are word-final obstruent clusters Marked for Iraqi EFL College Students?

2. Does the level of markedness increase with the increase of the length of the cluster in question?

To answer the above-stated questions, a test involving production tasks of the obstruent clusters is adopted as a tool to measure the markedness of the obstruent clusters. As such, production tasks are elicited from 60 Iraqi EFL Fourth-Year college students, Department of English, College of Arts-University of Baghdad for the academic year 2017-2018. The study aims at:

1. Proving that the EFL College students' mother tongue, which is Arabic, has the leading role in the high level of markedness in the present situation.

2. Identifying those strategies employed by Iraqi EFL College Students to simplify the marked clusters.

\section{OBSTRUENT CLUSTERS}

An obstruent cluster (OC, henceforth) represents a string of two or more obstruents (Singh and Singh, 1979: 16). Final obstruent clusters are much more complicated in comparison with initial and medial ones, because inflectional suffixes create complex codas. The following series of obstruents are accepted at the end of English words: fricative + fricative, stop + fricative, fricative + stop, and stop + stop as in apt, reefs, lapse, and lift (Hansen, 2006: 36).

In the occurrence of the two-member obstruent clusters finally, either an obstruent is preceded by a pre-final obstruent or followed by a post-final obstruent. /s/ is a pre-final obstruent as it is shown in "ask"/æsk/. Post-final obstruents are /s, $\mathrm{z}, \mathrm{t}, \mathrm{d}, \mathrm{p}, \Theta /$ as it is illustrated in the following examples: bets /bets/, beds /bedz/, backed /bækt//, and eighth/eitӨ/. There are two types of three consonant clusters:

1. Pre-final + final + post final as in helped $/$ helpt

2. Final + more than one post final consonant as in fifths/ fifӨs/(Roach, 2000: 71).

\section{PHONOTACTICS}

The item "phonotactics" has been coined by Robert Stockwell in 1954 (Bauer, and Kastovsky, 1988: 221). It is used in phonology to indicate the sequential arrangements of units of sounds in a language; it presents the rules of a phonological well-formed word (Crystal, 2008:s.v. phonotactics). Phonotactics shows that the phonemes are not combined randomly (Valimaa-Blum, 2005: 129). Phonotactics of a specific language is always imposing restrictions on the sequence and position of sounds in the words. Thus, particular combinations of sounds are accepted in one language but not in others (Brinton and Brinton, 2010: 59) and (Yule, 2010: 45).

\section{SIMPLIFICATION STRATEGIES}

A detailed explanation of the simplification strategies manifested in the marked OCs is presented in the following three sub-sections.

\section{OCs Reduction}

Obstruent clusters are usually subjected to reduction due to the universal tendency of speakers to overcome the difficulty of pronunciation (Wallace, 1972: 153, Hyman, 1975:18, and Hawkins, 1984: 16). EFLLs tend to delete an obstruent or insert a vowel between the members of obstruent clusters (Chapple, 2008: 12,15). Both of the epenthesis and the deletion of part of OC minimize OCs to shorter clusters, or to individual phonemes, as in "extra" which may be realised as/ Ikistr $\Lambda t /$, and /iksr $\Lambda t /$. Not only vowels are inserted between obstruents, but consonants are also made use of in there, as in "paved"/parvst/. Often, this happens if the language which is being learned has various combinations of consonants or vowels which differ from learner's L1 (Richard and Schmidt, 2010:s.v. epenthesis). One main reason underlies epenthesis:

1. Facilitating transitions between sounds which have multiple incompatibilities (Nathan, 2008: 81).

Epenthetic obstruents may be voiceless but not voiced (De lacy, 2007: 15,345). The deletion of part of OC represents a strategy resorted to by EFLLs where in specific circumstances an obstruent may have zero realisation especially in the rapid, connected speech as in "lifts" and " thousandths" in /hi lif Oauzands of buks/(Roach, 2009: 114).

\section{Articulatory Feature Change}

The articulatory feature change strategy indicates that the number of obstruents in OCs remains the same, but a certain change in the place or the manner of articulation happens (Arnold, 2009: 26). The changes in the place of articulation are clarified with reference to the processes: fronting and alveolarization. Whereas the changes in the manner of articulation are explicated with reference to the processes: stopping, deaffrication, voicing, and devoicing. These processes are illustrated below:

1. Fronting: a process in which the obstruent sound is produced utilizing articulators which are located more anteriorly than required for the target sound as in / $\mathrm{t} /$ which replaces /k/ in "extra" /Itsitrə/.

2. alveolarization: a process where the non-alveolar sounds are changed into alveolar ones as in "lectures" which is pronounced as /lost Jors/ in which the stop sound $/ \mathrm{k} /$ is turned into the fricative sound $/ \mathrm{s} /$.

3. Stopping: a process in which the affricates or fricatives are replaced by the stops as in "structures" which is pronounced as /sitr $\Lambda$ kts/ where the affricate $/ \mathrm{t} \mathrm{f} /$ is produced as $/ \mathrm{t} /$.

4. Deaffrication: a process represents the production of a homorganic fricative sound instead of an affricate one 
as in "snached" /snæft/ where the voiceless affricate /t $\mathrm{f} /$ is replaced by the voiceless fricative $/ \mathrm{J} /$.

5. Voicing: a process indicates changing a voiceless obstruent into a voiced one as in "transcription" which is pronounced as "trınzkrip $\int \mathrm{m} /$ in which the voiced fricative $/ z /$ is produced instead of the voiceless counterpart.

6. Devoicing: a process indicates the production of voiceless obstruents instead of voiced ones as in pronouncing /v/ as /f/ in "calves" /ka:lfs/ (Waengler, 2009: 264, 265, 266, 267).

Inverting the order of the members of the obstruent cluster is included within the articulatory feature change strategy as well as in "tax"/task/ (Arnold, 2009: 26)

\section{Deletion of Whole OC}

The deletion of whole OC strategy means omitting the entire cluster as in "extract" and "coughs" which are pronounced as $/ \mathrm{Ikstr} \Lambda /$ and $/ \mathrm{kJ} /$. In these examples the two-member FOCs /kt/ and /fs/ are removed (Arnold, 2009: 27). Here, the whole cluster will be realised as zero, or an entirely different word will be produced instead of the required one as in "transformation" which is produced instead of "transcription". It is a typical strategy resorted to by EFLLs to avoid complex obstruent clusters; it increases in the casual connected speech, as in / $\mathrm{Oau} /$ which is a pronunciation provided for "thousandths" (Roach, 2009: 114).

\section{DATA ANALYSIS AND DISCUSSION}

\section{Two-member Final Obstruent Clusters}

The marked two-member Final Obstruent Clusters (FOCs, henceforth) (73\%) are exposed more frequently than the unmarked ones $(26.3 \%)$; the two-member FOCs $(0.6 \%)$ are rarely missed. Table 1 and Figure 1 display the frequencies and percentages of the subjects' unmarked, marked, and missed pronunciations. The marked two-member FOCs are modified predominantly via the articulatory feature change strategy $(54.7 \%)$, and sometimes via the deletion of part of FOC $(22.8 \%)$ and the epenthesis $(18.2 \%)$ strategies. Stop+ fricative cluster (SFC, henceforth) in "Width"

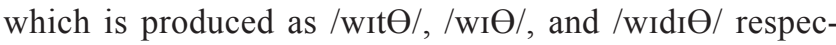
tively represents an example on such simplification strategies. The deletion of the whole FOC strategy (4.1\%) is rarely made use of as in as in /wei/. Table 2 and Figure 2 show the frequencies and percentages of the simplification strategies resorted to by the subjects to simplify the marked two-member FOCs.

\section{Three-member Final Obstruent Clusters}

The subjects' production of the marked three member FOCs $(93.3 \%)$ overcomes that of the unmarked ones $(6.6 \%)$; the three-member FOCs have not been missed by the subjects. Table 3 and Figure 3 display the frequencies and percentages of the subjects' unmarked, marked, and missed pronunciations. The deletion of part of the three-member FOCs strategy $(71.4 \%)$ is made use of frequently by the subjects while sim-
Table 1. The frequencies and percentages of the unmarked, marked, and missed pronunciations of the two- member FOCs

\begin{tabular}{lcc}
\hline & Frequencies & Percentages \\
\hline Unmarked & 79 & 26.3 \\
Marked & 219 & 73.0 \\
Missed & 2 & 0.6 \\
Totals & 300 & 99.9 \\
\hline
\end{tabular}

Table 2. The frequencies and percentages of the simplification strategies in the marked pronunciation of the two- member FOCs

\begin{tabular}{lcc}
\hline & Frequencies & Percentages \\
\hline Epenthesis & 40 & 18.2 \\
Deletion of part of FOC & 50 & 22.8 \\
Articulatory feature change & 120 & 54.7 \\
Deletion of whole FOC & 9 & 4.1 \\
Totals & 219 & 99.8 \\
\hline
\end{tabular}

Table 3. The frequencies and percentages of the unmarked, marked, and missed pronunciations of the three- member FOCs

\begin{tabular}{lcc}
\hline & Frequencies & Percentages \\
\hline Unmarked & 4 & 6.6 \\
Marked & 56 & 93.3 \\
Missed & 0 & 0 \\
Totals & 60 & 99.9 \\
\hline
\end{tabular}

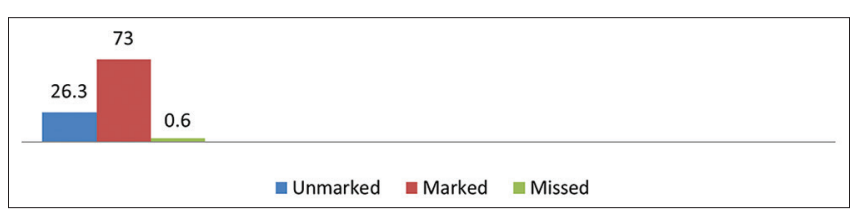

Figure 1. The unmarked, marked, and missed pronunciations of the two-member FOCs

\begin{tabular}{|l|l|}
\hline & \\
&
\end{tabular}

Figure 2. The simplification strategies of the marked pronunciation of the two-member FOCs

plifying the three-member FOCs as in fricative + fricative + fricative cluster (FFFC, henceforth) in "twelfths" /twelӨs/, /twelfs/, and /twelf/. The epenthesis strategy (21.4\%) is utilized sometimes by the subjects as in/twelfiӨs/. The articulatory feature change and the deletion of whole cluster strategies are rarely manifested in the subjects' production of the three member FOCs with a percentage of 5.3\% and $1.7 \%$ respectively. Table 4 and Figure 4 present the frequencies 
and percentages of the simplification strategies resorted to by the subjects to simplify the marked three-member FOCs.

\section{Four-member Final Obstruent Clusters}

The unmarked four-member FOCs $(5 \%)$ are produced rarely by the subjects, and the marked ones (95\%) are dominant. Subjects never miss the four-member FOCs. Table 5 and Figure 5 display the frequencies and percentages of the subjects' unmarked, marked, and missed pronunciations. The deletion of part of FOCs strategy $(78.9 \%)$ is most frequently used to simplify the marked four-member FOCs. For example, while pronouncing "sixths" as /sıks $\Theta /, / \mathrm{sik} \Theta \mathrm{s} /$, and $/ \mathrm{sik} \Theta /$, the subjects tend to delete/s/from stop + fricative+ fricative + fricative cluster (SFFFC, henceforth). The use of the epenthesis strategy $(21.0 \%)$ is made by the subjects in

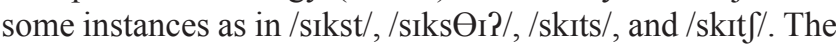
articulatory feature change and the deletion of whole fourFOCs strategies are not manifested. Table 6 and Figure 6 reveal the frequencies and percentages of the simplification strategies resorted to by the subjects to simplify the marked four-member FOCs.

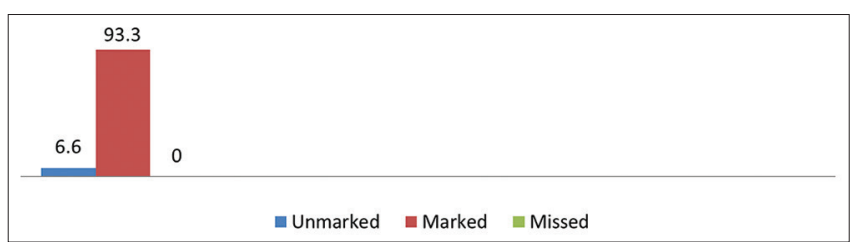

Figure 3. The unmarked, marked, and missed pronunciations of the three-member FOCs

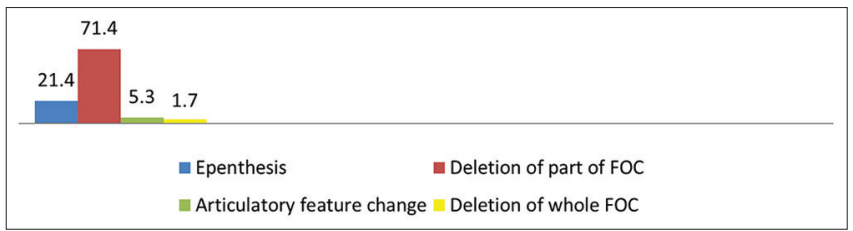

Figure 4. The simplification strategies of the marked pronunciation of the three-member FOCs

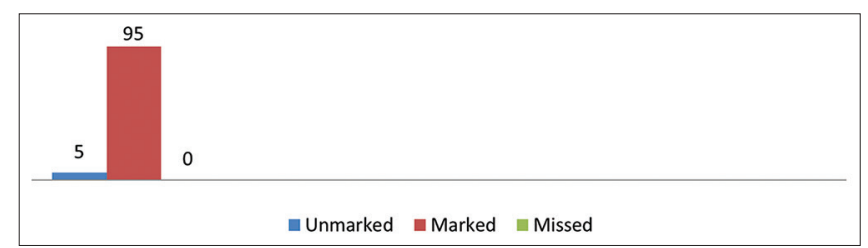

Figure 5. The unmarked, marked, and missed pronunciations of the four-member FOCs

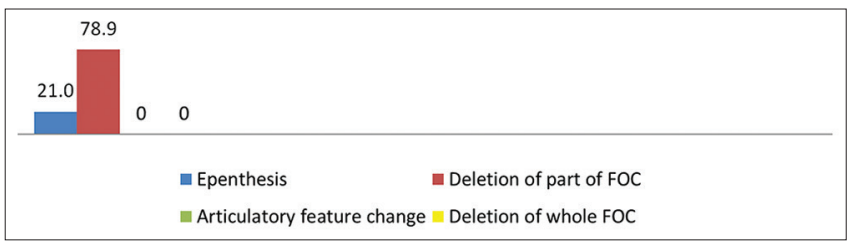

Figure 6. The simplification strategies of the marked pronunciation of the four-member FOCs
A consideration of the subjects' pronunciations of the two-member, the three-member, and the four-member FOCs shows that the different orderings of such clusters prove to be a variation in the levels of markedness. This may lead one to present these levels as a reflection of a hierarchy of least and most marked types of FOCs. This is shown in Figure 7:

SFC is marked for $(76.6 \%)$ of the subjects, because its second constituent (the fricative sound) is universally more marked than the stop sound (Lass, 1984: 154). FFFC is marked for $(93.3 \%)$ of the subjects, because all the members which constitute the cluster are marked. SFFFC is the most marked type of FOCs for (95\%) of the subjects. This can be attributed to the increased length of the cluster, and to the fact that fricatives, which are universally more marked, dominate the stop sound which represents the first member. This hierarchy is drawn depending on the diagnostics of markedness "frequency, distribution, simplicity, and the order of learning and cognitive complexity". SFC is a frequent, simple cluster, and has a distribution in both of English and Arabic. So, it will occupy the initial place in the order of learning English OCs, and it will be less complex than the other clusters. FFFC and SFFFC are infrequent clusters; they are available only in English but not in Arabic. Thus, they will be cognitively more complex than SFC and learned later

Table 4. The frequencies and percentages of the simplification strategies in the marked pronunciation of the three- member FOCs

\begin{tabular}{lcc}
\hline & Frequencies & Percentages \\
\hline Epenthesis & 12 & 21.4 \\
Deletion of part of FOC & 40 & 71.4 \\
Articulatory feature change & 3 & 5.3 \\
Deletion of whole FOC & 1 & 1.7 \\
Totals & 56 & 99.8 \\
\hline
\end{tabular}

Table 5. The frequencies and percentages of the unmarked, marked, and missed pronunciations of the four- member FOCs

\begin{tabular}{lcc}
\hline & Frequencies & Percentages \\
\hline Unmarked & 3 & 5 \\
Marked & 57 & 95 \\
Missed & 0 & 0 \\
Totals & 60 & 100 \\
\hline
\end{tabular}

Table 6. The frequencies and percentages of the simplification strategies in the marked pronunciation of the four- member FOCs

\begin{tabular}{lcc}
\hline & Frequencies & Percentages \\
\hline Epenthesis & 12 & 21.0 \\
Deletion of part of FOC & 45 & 78.9 \\
Articulatory feature change & 0 & 0 \\
Deletion of whole FOC & 0 & 0 \\
Totals & 57 & 99.9 \\
\hline
\end{tabular}




$$
\mathrm{SFC}<\mathrm{FFFC}<\mathrm{SFFFC}
$$

Figure 7. A hierarchy of least and most marked FOCs

in the process of learning English OCs.

\section{CONCLUSIONS}

After analysing and discussing OCs in the final position of words, the following conclusions are drawn:

1. FOCs are marked due to the fact that the obstruents are universally marked in the coda.

2. The extensive use of the simplification strategies while pronouncing FOCs by Iraqi Arabic EFLLs represents a tool to convert the English marked OCs to the Arabic unmarked ones.

3. It is an evidently proved a fact that the EFL College students' mother tongue, which is Arabic, has the leading role in the high level of markedness in the present situation. This is because Arabic disfavours obstruent clusters of more than two members.

4. The four-member OCs are more marked than the three-member OCs which are in turn more marked than the two-member OCs.

5. The simplification strategies (epenthesis and articulatory feature change) used by EFLLs can be explained with reference to the "recoverability" principle. This principle allows the occurrence of a change within the cluster (devoicing / $/$ / in "paved" for example) instead of losing the whole cluster.

6. The utilization of the epenthesis strategy will increase while pronouncing decontextualised OCs, when the subjects are required to focus on the form of words. Whereas the deletion of part of OCs and the articulatory feature change strategies will be manifested more than the preceding strategy while pronouncing contextualised OCs where the subjects focus on the content of words.

\section{REFERENCES}

Arnold, A. (2009). Pronouncing three-Segment final Consonants clusters, Hamline University. https://www.hamline.edu (accessed February 21, 2018).

Battistella, E. L. (1990). Markedness: The Evaluative Superstructure of Language. Albany: The State University of New York Press.

Bauer, G., \& Kastovsky, D. (1988). Luick Revisited: Papers Read at The Luick-Symposium at Schloss. Germany: Gunter Narr Verlag.

Brinton, L. J. and Brinton, D. M. (2010). The Linguistic Structure of Modern English. "Amsterdam and Philadelphia: John Benjamins.

Callies, M. \& Gutenberg, G. (2013). “Markedness”. In Robinson, P. (ed.). Routledge Encyclopedia of Second Language Acquisition. New York: Routledge. 406-409.

Chappell, M. (2008). First-Language Transfer and Universal Markedness in Second Language production and per- ception of Word Final Obstruent and Obstruent Clusters. MA thesis, University of Florida. UFE0022664< ufdc. ufdc.ufl.edu (accessed January 15, 2018).

Crystal, D. (2008). A dictionary of Linguistics and Phonetics. (6 ${ }^{\text {th }}$ ed.). Oxford: Blackwell.

De Lacy, P. (2006). Markedness: Reduction and Reservation in Phonology. Cambridge University Press: United States of America.

(2007). The Cambridge Handbook of Phonology. United States of America: Cambridge University Press.

Ferguson, C.A. (1984). "Repertoire Universals, Markedness, and Second Language Acquisition". In Rutherford, W.E. (ed.). Language Universals and Second Language Acquisition. Amsterdam: John Bengamins Publishing Company. 247-285.

Greenberg, J. H. (1966). Language Universal. The Hague: Mouton.

Hansen, J.G. (2006). Acquiring a Non-Native Phonology: Linguistic Constraints and Barriers. London: Continuum.

Hawkins, P. (1984). Introduction Phonology. London: Hutchinson and Co. Ltd.

Hyman, L. (1975). Phonology Theory and Analysis. New York: Holt, Rinhart, and Winston.

Lass, R. (1984). Phonology: An Introduction to Basic Concepts. Cambridge: Cambridge University Press.

Lyons, J. (1977). Semantics. Cambridge: Cambridge University Press.

Nathan, G. (2008). Phonology: A Cognitive Grammar Introduction. Amsterdam and Philadelphia: John Benjamins.

Richard, J and Schmidt, R. (2010). Dictionary of Language teaching and Applied Linguistics. United Kingdom: Copyright Licensing Agency Ltd.

Roach, P. (2000). English Phonetics and Phonology: A Practical Course. ( $3^{\text {rd }}$ ed.). Cambridge: Cambridge University Press.

----------(2009). English Phonetics and Phonology: A Practical Course. ( $4^{\text {th }}$ ed.). Cambridge: Cambridge University Press.

Singh, K. and Singh, S. (1979). Phonetics: Principles and Practice. Baltimore: University Park Press.

Valimaa-Blum, R. (2005). Cognitive Phonology in Construction Grammar: Analytic Tools for Students of English. Berlin: Mouton de Gruyter.

Waengler, J. (2009). Introduction to Phonetics and Phonology: From Concepts to Transcription. United States of America: Pearson Education, Inc.

Wallace, R. Betty, J, and Clifford, H. (1972). Manual of English Pronunciation. $3^{\text {rd }}$ ed. New York: Holt, Rinhart, and Winston.

Yule, G. (2010). The Study of Language. Cambridge: Cambridge University Press. 


\section{APPENDIX}

\section{Elicitation Tasks}

Task 1: Pronounce the following words:

Width

Calves

Paved

Charged

Twelfths

Sixths

\section{Task 2: Pronounce the following sentences:}

1. The introduction of the new tax caused a storm of protest.

2. He lifts thousandths of boxes.

3. Japan has been industrialized in the late nineteenth century.

4. Linguists explain difficult structures.

5. Ahmed leaves the country.

Task 3: Pronounce each underlined word once individually then repeat it within the provided sentence:

1. Few students stay calm during all lectures.

2. When Ahmed snatched his phone, Suha said "I don't care" and shrugged.

3. She bought new clothes.

4. John directly fetched extra firewood.

5. I have glimpsed a white handkerchief. 